\title{
The Trojan Horse of International Markets: Manipulating Websites in Access Economy
}

\author{
Elham Mohammed Al-Oraij ${ }^{1}$ \& Abdulrahman Al-Aali ${ }^{1}$ \\ ${ }^{1}$ King Saud University KSU, Kingdom of Saudi Arabia \\ Correspondence: Elham Mohammed Al-Oraij, King Saud University KSU, Kingdom of Saudi Arabia. E-mail: \\ eloraij@gmail.com
}

Received: April 21, 2016

Accepted: May 18, 2016

Online Published: June 18, 2016

doi:10.5539/ijbm.v11n7p172

URL: http://dx.doi.org/10.5539/ijbm.v11n7p172

\begin{abstract}
The concept of access economy is relatively new, evolving at the beginning of 2015 from the sharing economy concept. Further, it marks a new trend in the business world. Building on the work of Mazaheri et al. (2014), this paper aims to expand the proposed model to the access economy world. This paper has two goals: to uncover more elements of the new access economy enterprises, and to further falsify the findings of Mazaheri et al. (2014) model. With the help of the access economy principals, it was possible to expand the model to the access economy domain. Limitations and areas for future research are discussed afterwards.
\end{abstract}

Keywords: access economy, websites, atmospheric cues, sharing economy, principles

\section{Introduction}

Airbnb, Zipcar, JustRide, Zoomcar, EliteHeads and Uber, all are well-known brands of commercial enterprises. These names reached the peak of fame worldwide by 2015. At the beginning, activities of these enterprises were grouped under the umbrella of sharing economy. Sharing economy is a hybrid market model which refers to peer-to-peer-based sharing of access to goods and services (Hamari et al., 2015; Puschmann \& Alt, 2016). This was valid until Eckhardt, \& Bardhi (2015) announced in their article in Harvard Business Review (HBR) that it is not sharing anymore but an economic exchange "When "sharing" is market-mediated - when a company is an intermediary between consumers who don't know each other - it is no longer sharing at all. Rather, consumers are paying to access someone else's goods or services for a particular period of time. It is an economic exchange, and consumers are after utilitarian, rather than social, value". With this distinction, it is rational to consider the activities of these enterprises as access economy not sharing economy. The debate is still a living issue as some scholars still refer to it as sharing economy (Cusumano, 2015; Posen, 2015; Rauch, \& Schleicher, 2015; Zervas et al., 2015; Dakhlia et al., 2016), while others (Meelen, \& Frenken, 2015; Mathe, 2015; Assenova et al., 2016) believe that HBR's access economy fits this category better. In this current study, we are going to follow the HBR perspective without going further into this debate as it makes more sense. Due to the scarce literature available on access economy, literature on sharing economy will be a credible reference as it discusses the same phenomenon. Access economy enterprises rely on websites to offer its services to different markets; making it the more reason to try addressing the role of its atmospheric cues as the gate to access new markets. To further explain the mechanism of access economy operations, a demonstration is presented in (Figure 1).

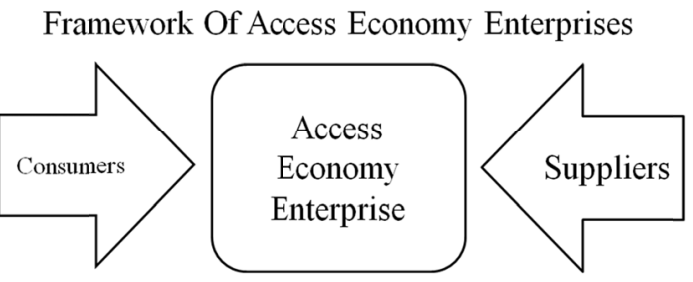

Figure 1. Access economy enterprises framework

Source: Edited from Demary (2015). 


\section{Literature Review}

\subsection{Website Atmospheric Cues of Access Economy Enterprises and New International Markets}

The concept of access economy wasn't addressed before 2015 when HBR acknowledged it (Eckhardt \& Bardhi, 2015). Even when it was referred to as sharing economy enterprises, there is still little literature available. The earliest found material in literature, dates back to 2012, which is logical as the pioneers of this industry (Uber and Airbnb) operated the same year as the great financial crisis in 2008. Most of the literature is in the form of case studies e.g. (Wirtz \& Tang, 2015; Rogers, 2015; Rempel, 2014; Harding et al., 2015; Kaplan \& Nadler, 2015). This paper will try building on the information provided by the literature to propose a link between this relatively new phenomenon, international business, and Mazaheri et al. (2014) model of website atmospheric cues with online behavior.

\subsection{Access Economy Enterprises and International Markets}

In what seems like the blink of an eye, access economy pioneers soon reached an international level. Pioneers like Uber and Airbnb are currently operating in 190 and 58 countries respectively. Other enterprises - newly formed - are also seeking their way towards becoming international after establishing a good base in their home countries. In order to expand into more international markets, they need to sharpen their capabilities. In his dissertation, Le (2015) discussed what can be called the "Sharing Economy Principles". As previously agreed upon, the title was modified to fit the theoretical framework of this paper. It is now called the "Access Economy Principles" and they were arranged in the model presented in Table 1. These principles are essential for these enterprises to survive either locally or internationally. They face tremendous challenges from well-established industries, governmental regulations, public opinion, cultural differences, established norms, and consumers' preferences. These are major forces that can provide either a big chance or a major threat blocking its reach to its targeted consumers. The first principle, "Trust and Reputation", is what Botsman (2012) heavily emphasized on it being the currency of access economy. Since access economy enterprises took full advantage of modern technology, it needs to emphasize on "reputation capital" as it is the only credibility for these enterprises. Reputation Capital was defined as "the worth of your reputation - intentions, capabilities and values - across communities and marketplaces" (Botsman \& Rogers, 2012). The second principle, "Access Over Ownership", refers to the fact that items traded by the two sides of the access economy enterprise operations are not owned by the consumer. Rather, consumers only gain access to the item and utilize it for a period of time for a lower cost (Botsman \& Rogers, 2012). The third principle. "Transparent and Open Information", means that a disclosure of all information about the item exchanged is credible, honest and clear (Botsman \& Rogers, 2012). The last principle, "No Wasted Value", emphasizes one of the greatest advantages of access economy enterprises. The principle of " No Wasted Value" guarantees that the supplier's owned item will be better utilized with extra money as well (Botsman \& Rogers, 2012).

Table 1. Principles of access economy

\begin{tabular}{ll}
\cline { 2 - 2 } Trust and Reputation & Access Over Ownership \\
\cline { 2 - 3 } Transparent and open Information & No Wasted Value \\
\cline { 2 - 2 } \\
Source: Generated from Botsman \& Rogers (2012).
\end{tabular}

There are many factors that encourage the expansion of access economy enterprises such as technological advancement (Owyang, 2013), population expansion (Finley, 2013), and economical fluctuation (Botsman \& Rogers, 2010). On the other hand, there are still many obstacles that might prevent international expansion. Government regulations (Bond, 2015) for example, is one barrier that needs to be fully addressed by access economy enterprises especially in the targeted country. In order to access that new market, access economy enterprises needs to consider the governmental regulations of that country before starting the expansion movement. Another issue that needs to be considered is the cultural factor (Gountas \& Gountas, 2015). Access economy enterprises need to be open to cultural differences to gain access to these new markets. There are other factors that need to be considered by access economy enterprises but this study will only focus on these two major elements.

\subsection{Websites Atmospheric Cues Effect on Target Market Decision}

The influence of websites atmospheric cues on consumers decision has been widely discussed in the literature (for example, Dailey, 2004; Eroglu et al., 2001, 2003; Hausman \& Siekpe, 2009; Mummalaneni, 2005; Richard, 
2005). Mazaheri et al. (2014) developed a theoretical model (Figure 2) that was examined and shown to be valid (Mazaheri et al., 2014). The model divided the atmospheric cues into three categories. Emotions resulting from surfing the websites were divided based on Mehrabian and Russell's (1974) PAD framework (pleasure, arousal, and dominance). The perception of the atmospheric cues was divided to site informativeness (Hoffman \& Novak, 1996), site entertainment (Chen \& Wells, 1999), and site effectiveness (Bell \& Tang, 1998). The types of tangibility of websites were based on the work of Laroche et al. (2001) and divided into: physical tangibility, specificity, and mental tangibility. Consumers attitudes towards these atmospheric cues were relative to the site itself and the services provided through it. It is worthwhile to investigate if this limited model can be extended to cover the access economy enterprises.

\subsection{Website Atmospheric Cues to Access New International Markets}

The aim of this paper is to expand the website atmospheric cues framework to the domain of access economy enterprises. In the attempt to integrate the previous models into a single model representing the proposed theory, the primary model is developed as demonstrated in (Figure 3).

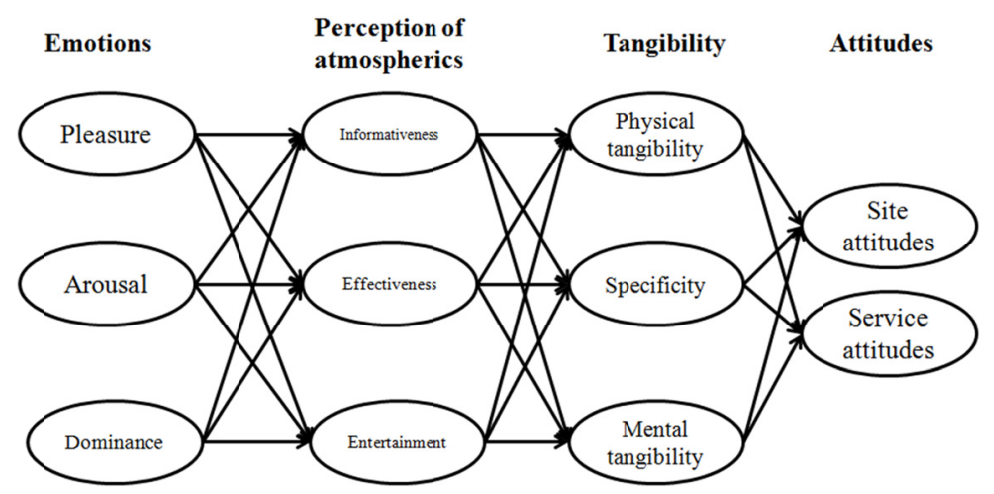

Figure 2. Websites atmospheric cues model

Source: Mazaheri et al. (2014).

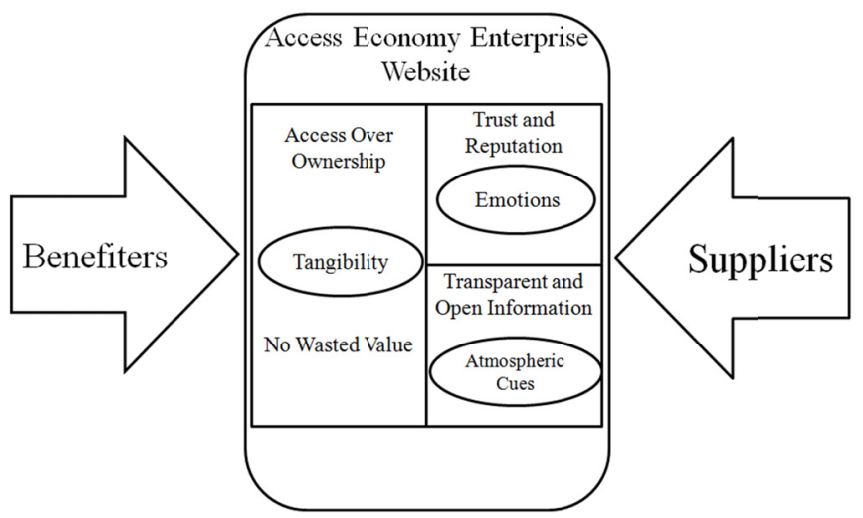

Figure 3. Access economy enterprises website model

Source: Compiled by authors.

\section{Merging the Access Economy Enterprises Principles and the Website Atmospheric Cues Framework}

It is now clear that access economy enterprises operate as intermediaries between different suppliers and consumers across the globe. It matches the closest consumers to the most suited available supplier. This matching is achieved through a dynamic database of registered suppliers and demanding consumers. To best utilize these dynamic databases, special and careful attention needs to be directed to its websites. Access economy enterprises' websites need to clearly demonstrate its principles to the interested parties. Table 2 represents how the authors view the distribution of websites atmospheric cues on access economy enterprises principles and these enterprises targeted direction. 
Table 2. Distribution of websites atmospheric cues on access economy enterprises principles and its targeted direction

\begin{tabular}{lll}
\hline Principle & Website Cue & Target \\
\hline Trust and Reputation & Emotions & Suppliers + Benefiters \\
Access over Ownership & Tangibility & Benefiters \\
Transparent and Open Information & Atmospheric Cues & Benefiters \\
No Wasted Value & Tangibility & Suppliers \\
\hline
\end{tabular}

Source: Inferred by the authors from the literature.

\section{a) Trust and Reputation with Emotion Cues}

The "emotions" cue in Mehrabian and Russell (1974) PAD framework, reflected three powers of a website: "pleasure"; an indicator of the website "likeability" (Poels \& Dewitte, 2008), "arousal"; an indicator of the website "motivational power" (Poels \& Dewitte, 2008), and "dominance"; an indicator of the website "controlling power" (Mazaheri et al., 2011). Linking this to the principles of access economy enterprises, it can be found that Botsman and Rogers' (2012) definition of reputation capital is the most suited to the "Emotions" cue. This justifies the following proposition:

Proposition 1: The access economy enterprise "Reputation and Trust" principle is reflected in the "Emotions" cue of websites atmospheric cues model.

\section{b) Access Over Ownership and No Wasted Value with Tangibility}

The "Tangibility" cue in the work of Laroche et al. (2001), reflected three dimensions of tangibility: physical tangibility; "access to the product by senses", specificity; "the consumer's ability to define the product" (Mazaheri et al., 2014), and mental tangibility (Laroche et al., 2004); "the ability to visualize the particular product mentally" (Mazaheri et al., 2014). Linking this to the principles of access economy enterprises, it can be assumed that Le's (2015) description "access over ownership" and "no wasted value" are the most suited to this category of tangibility. Access over ownership represents the "physical tangibility" aspect as the consumer can access the product without actually owning it. On the other hand, "no wasted value" represents the aspects of "specificity" and "mental tangibility" as consumers dealing with this website fully understand the service provided justifying the following propositions:

Proposition 2a: The access economy enterprise "Access Over Ownership" principle is reflected in the "tangibility" cue of websites atmospheric cues model.

Proposition 2b: The access economy enterprise "No Wasted Value" principle is reflected in the "tangibility" cue of websites atmospheric cues model.

\section{c) Transparent and Open Information with Perception of the Cues}

The perception of websites atmospheric cues in Mazaheri et al. (2014) model, was based on the works of Richard (2005) and Mazaheri et al. (2011). Site informativeness reflects the availability of the desired information (Hoffman \& Novak, 1996), site entertainment reflects the level of interactiveness it has (Chen \& Wells, 1999), and site effectiveness reflects the website's information's accuracy, completeness, updatedness and relevance (Bell \& Tang, 1998). Back to the access economy enterprises principles, the meaning of "Transparent and Open Information" by Le (2015) makes a best match; legitimating the third proposal.

Proposition 3: the access economy enterprise "Transparent and Open Information" principal is reflected in the "perception of websites atmospherics" cue of websites atmospheric cues model.

\section{Relating the Cues Principles to the Targeted Parties}

After classifying the websites' atmospheric cues on the principals of access economy enterprises, the next step is to define the consumers of these enterprises as suppliers or benefiters. Both parties are considered as consumers to the services of these enterprises. The suppliers are consumers that offer the assets needed by these enterprises through their websites. Benefiters, on the other hand, are the parties that access and utilize these assets offered by the suppliers through the same websites. Bearing this distinction in mind, the proposed theory is further expanding to cover these two interested parties of consumers.

\section{a) No Wasted Value and Trust and Reputation to Suppliers Consumers}

After assigning the website atmospheric cues "Emotions" and "Tangibility" to the "Trust and Reputation" and "No Wasted Value" principles, respectively, it becomes easier to assign them to the appropriate party of 
consumers "Supplier". The authors believe that the "Supplier" is a consumer to the services of the website offering an asset to the most appropriate "Benefiter". The supplier guaranties that his owned asset will be further utilized for an extra value. He is also assured that his asset is being offered to a credible entity that will not waste his right of a cash compensation. This paves the way to two propositions:

Proposition 4a: the access economy enterprise "Trust and Reputation" principle and "Emotions" cue are directed to the benefit of the supplier consumer.

Proposition 4b: the access economy enterprise "No Wasted Value" principle and "Tangibility" cue are directed to the benefit of the supplier consumer.

\section{b) Transparent and Open Information, Access Over Ownership, and Trust and Reputation to Benefiters} Consumers

The atmospheric cues "Emotions", "Perception of Atmospherics", and "Tangibility" were assigned to the "Trust and Reputation", "Transparent and Open Information", and "Access Over Ownership" principals respectively. The other category of access economy enterprises' websites consumers are the "Benefiter" consumers. The benefiter is a consumer to the services of the website offering by accessing the asset offered by the most suitable supplier consumer. The benefiter is satisfied with the utilization of the asset he desired from a trusted source, for a lower price, and without the liability of ownership. Matters of security are guaranteed due to the open and transparent information of the suppliers. Thus, three propositions can be presented:

Proposition 5a: the access economy enterprise "Trust and Reputation" principle and "Emotions" cue are directed to the benefit of the benefiter consumer.

Proposition 5b: the access economy enterprise "Transparent and Open Information" principle and "Perception of Atmospherics" cue are directed to the benefit of the benefiter consumer.

Proposition 5c: the access economy enterprise "Access Over Ownership" principle and "Tangibility" cue are directed to the benefit of the benefiter consumer.

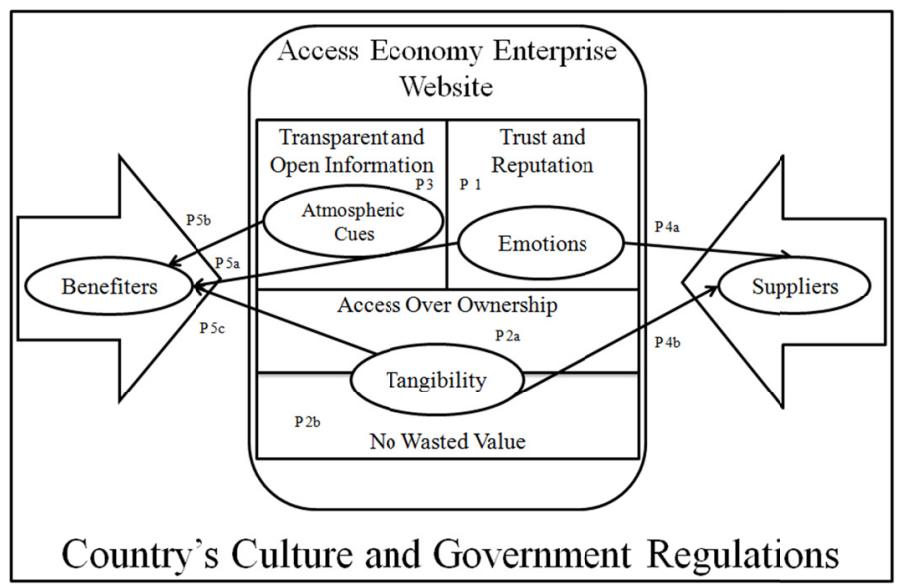

Figure 5. A proposed model for access economy enterprise's website model

Source: The Authors.

\section{Conclusion}

Like the Trojan horse from the legends, access economy enterprises gained rapid access to many locations worldwide. They changed the lifestyles, social structures, and perceptions of all the locations they operate in. This made it earn a place in Time's "10 ideas that will change the world". It is something we witness and experience everyday as long as technology and the internet are available. Being a new phenomenon or the new trend in business, doesn't deny the fact of access economy being interesting. This paper aimed at further uncovering this new phenomenon by using Mazaheri's et al. (2014) model of the website's atmospheric cues. The attempt seems possible after joining the principles of access economy enterprises with websites' cues. This serves as a further confirmation to the findings of Mazaheri et al. (2014). Consumers' decisions are indeed influenced by what they receive from websites atmospheric cues. This paper also confirms the influence of culture on these decisions. Further, this paper also helped in uncovering more aspects of the new access economy 
phenomenon. This is not the end, however. The findings of this paper paves the way for further avenues of future works. The findings of this paper are conceptual, making it necessary to conduct an empirical application to confirm it as this is not the focus of this paper. Future works can try to test the findings in real world contexts. Another area for future works is to develop an improved measure of websites' atmospheric cues reflecting the principles of access economy enterprises. The new access economy enterprises phenomenon is still vague and vast. This paper only uncovered the part that is related to Mazaheri et al. (2014) website atmospheric cues model.

Future works can further uncover this phenomenon from different angles. One angle is to acknowledge the inclusion of these enterprises under the access economy umbrella and not the sharing economy, or proving the opposite. Another angle is to further analyze the characteristics of these enterprises as a category and not a single firm's cases. A third angle is to analyze the clash between these access economy enterprises and different government regulations and different cultures - around the world or within the same country. Future research areas can also be directed to analyze the technologies used by these enterprises and their effects. Measurement of the access economy enterprises may be developed in future works. The principles of access economy can also be expanded by uncovering new principles. Another direction for future research is to apply other models on access economy enterprises. The mechanisms and management structures followed in these enterprises are other areas for future research. Also, Mazaheri et al. (2014) model can be further falsified by applying it to other contexts. It can also be replicated with the two types of consumers (suppliers and benefiters) as respondents. Even though this paper is suffering from the scarce availability of literature, it is the hope of the authors that it will pave the road to rich literature that will contribute more to the business and management paradigm. Access economy enterprises are a new business form that rapidly expanded internationally. This makes it clear that the world is not vast anymore but "It's a small world after all".

\section{References}

Assenova, V., Best, J., Cagney, M., Ellenoff, D., Karas, K., Moon, J., \& Sorenson, O. (2016). The Present and Future of Crowdfunding. California Management Review, 58(2), 125-135. http://dx.doi.org/10.1525/cmr.2016.58.2.125

Bell, H., \& Tang, N. K. H. (1998). The effectiveness of commercial internet web sites: A user's perspective. Internet Research, 8(3), 219-228. http://dx.doi.org/10.1108/10662249810217768

Bond, A. T. (2015). An app for that: Local governments and the rise of the sharing economy. Notre Dame Law Review, 90(2), 77-96.

Botsman, R. (2012). The case for collaborative consumption. TED, Sydney, Australia, May.

Botsman, R., \& Rogers, R. (2012). What's mine is yours: How collaborative consumption is changing the way we live. London: Collins.

Chen, Q., \& Wells, W. D. (1999). Attitude toward the site. Journal of Advanced Research, 39(5), 27-38.

Cusumano, M. A. (2015). How traditional firms must compete in the sharing economy. Communications of the $A C M, 58(1), 32-34$. http://dx.doi.org/10.1145/2693199

Dailey, L. C. (2004). Navigational web atmospherics: Explaining the influence of restrictive navigation cues. Journal of Business Research, 57(7), 795-803. http://dx.doi.org/10.1016/S0148-2963(02)00364-8

Dakhlia, S., Davila, A., \& Cumbie, B. (2016). Trust, but Verify: The Role of ICTs in the Sharing Economy. In Information and Communication Technologies in Organizations and Society (pp. 303-311). Springer International Publishing. http://dx.doi.org/10.1007/978-3-319-28907-6_20

Demary, V. (2015). Competition in the sharing economy (No. 19/2015). IW policy paper.

Eckhardt, G., \& Bardhi, F. (2015). The Sharing Economy Isn’t About Sharing at All. Harvard Business Review (28 January). https://hbr.org/2015/01/the-sharing-economy-isnt-about-sharing-at-all

Eroglu, S. A., Machleit, K. A., \& Davis, L. M. (2001). Atmospheric qualities of online retailing: A conceptual model and implications. Journal of Business Research, 54(2), 177-184. http://dx.doi.org/10.1016/S0148-2963(99)00087-9

Eroglu, S. A., Machleit, K. A., \& Davis, L. M. (2003). Empirical testing of a model of online store atmospherics and shoppers responses. Psychology and Marketing, 20(2), 139-150. http://dx.doi.org/10.1002/mar.10064

Finley, K. (2013). Trust in the sharing economy: an exploratory study. Coventry: Center for cultural policy studies. The University of Warwick, UK. Retrieved from https://www2.warwick.ac.uk/fac/arts/theatre_s/cp/research/publications/madiss/ccps_a4_ma_gmc_kf_3.pdf 
Gountas, J., \& Gountas, S. (2015). Subjective and confirmatory personal introspections of cultural city holidays. International Journal of Culture, Tourism and Hospitality Research, 9(4), 399-408. http://dx.doi.org/10.1108/IJCTHR-08-2015-0093

Hamari, J., Sjöklint, M., \& Ukkonen, A. (2015). The sharing economy: Why people participate in collaborative consumption. Journal of the Association for Information Science and Technology. http://dx.doi.org/10.1002/asi.23552

Harding, S., Kandlikar, M., \& Gulati, S. (2016). Taxi apps, regulation, and the market for taxi journeys. Transportation Research Part A: Policy and Practice, 88, 15-25. Retrieved from http://www.sciencedirect.com/science/article/pii/S0965856416302191

Hausman, A. V., \& Siekpe, J. S. (2009). The effect of web interface features on consumer online purchase intentions. Journal of Business Research, 62, 5-13. http://dx.doi.org/10.1016/j.jbusres.2008.01.018

Hoffman, D. L., \& Novak, T. P. (1996). Marketing in hypermedia computer-mediated environments: Conceptual foundations. Journal of Marketing, 60(3), 50-68. http://dx.doi.org/10.2307/1251841

Kaplan, R. A., \& Nadler, M. L. (2015). Airbnb: A Case Study in Occupancy Regulation and Taxation. U. Chi. L. Rev. Dialogue, 82, 103.

Laroche, M., Bergeron, J., \& Goutaland, C. (2001). A three-dimensional scale of intangibility. Journal of Service Research, 4(1), 26-38. http://dx.doi.org/10.1177/109467050141003

Laroche, M., McDougall, G. H., Bergeron, J., \& Yang, Z. (2004). Exploring how intangibility affects perceived risk. Journal of Service Research, 6(4), 373-389. http://dx.doi.org/10.1177/1094670503262955

Le, B. D. (2015). Challenges in entering Vietnamese market for companies in the sharing economy.

Mathe, H. (2015). Living Innovation: Competing in the 21st Century Access Economy. World Scientific Publishing Co Pte Ltd.

Mazaheri, E., Richard, M. O., \& Laroche, M. (2011). Online consumer behavior: A comparison between Canadian and Asian website visitors. Journal of Business Research, 64, 958-965. http://dx.doi.org/10.1016/j.jbusres.2010.11.018

Mazaheri, E., Richard, M. O., Laroche, M., \& Ueltschy, L. C. (2014). The influence of culture, emotions, intangibility, and atmospheric cues on online behavior. Journal of Business Research, 67(3), 253-259. http://dx.doi.org/10.1016/j.jbusres.2013.05.011

Meelen, T., \& Frenken, K. (2015). Stop saying Uber is part of the sharing economy. An article produced for Fast Company, 30(1), 2015.

Mehrabian, A., \& Russell, J. A. (1974). The basic emotional impact of environments. Perceptual and Motor Skills, 38, 283-301.

Mummalaneni, V. (2005). An empirical investigation of Web site characteristics, consumer emotional states and on-line shopping behaviors. Journal of Business Research, 58, 526-532. http://dx.doi.org/10.1016/S0148-2963(03)00143-7

Owyang, J. (2013). The collaborative economy. San Francisco: Altimeter group.

Poels, K., \& Dewitte, S. (2008). Getting a line on print ads. Journal of Advertising, 37(4), 63-74. http://dx.doi.org/ 10.2753/JOA0091-3367370405

Posen, H. A. (2015). Ridesharing in the Sharing Economy: Should Regulators Impose Uber Regulations on Uber. Iowa Law Review, 101, 405-433.

Puschmann, T., \& Alt, R. (2016). Sharing economy. Business \& Information Systems Engineering, 1-7.

Rauch, D. E., \& Schleicher, D. (2015). Like Uber, But for Local Governmental Policy: The Future of Local Regulation of the "Sharing Economy". George Mason Law \& Economics Research Paper, (15-01). http://dx.doi.org/10.2139/ssrn.2549919

Rempel, J. (2014). A Review of Uber, the Growing Alternative to Traditional Taxi Service.

Richard, M. O. (2005). Modeling the impact of internet atmospherics on surfer behavior. Journal of Business Research, 58(12), 1632-1642. http://dx.doi.org/10.1016/j.jbusres.2004.07.009

Rogers, B. (2015). The social costs of Uber. University of Chicago Law Review. http://dx.doi.org/10.2139/ssrn.2608017 
Walsh, B. (2011). 10 Ideas That Will Change the World. TIME.

Wirtz, J., \& Tang, C. (2016). UBER: Competing As Market Leader In The US Versus Being A Distant Second In China. In W. Jochen \& L. Christopher (Eds.), Services Marketing: People, Technology, Strategy (8th ed.). Singapore: World Scientific (forthcoming).

Zervas, G., Proserpio, D., \& Byers, J. (2015). The rise of the sharing economy: Estimating the impact of Airbnb on the hotel industry. Boston $U$. School of Management Research Paper. http://dx.doi.org/10.2139/ssrn.2366898

\section{Copyrights}

Copyright for this article is retained by the author(s), with first publication rights granted to the journal.

This is an open-access article distributed under the terms and conditions of the Creative Commons Attribution license (http://creativecommons.org/licenses/by/3.0/). 